\title{
BLAISE PASCAL: OS LIMITES DO MÉTODO GEOMÉTRICO E A NOÇÃO DE "CORAÇÃO"
}

João Emiliano Fortaleza de AQUINO ${ }^{1}$

Ao Daniel Fortaleza, que, nesses tempos primaveris da vida, experimenta non more geometrico os saberes e os sabores do coração

- RESUMO: Este estudo pretende pensar o problema do conhecimento em Blaise Pascal, atentando para sua concepção do método geométrico aplicado ao conhecimento da natureza e das técnicas e para seu esforço por uma outra forma de conhecimento que possa ser aplicada às realidades "sobrenaturais" (a fé, o homem, a moral, os costumes, a política). Para tanto, o presente estudo articula uma análise dos ensaios pascalianos Préface. Sur le Traité du vide, De l'esprit géometrique, De l'art de persuader, e de alguns fragmentos dos Pensées.

- PALAVRAS-CHAVE: conhecimento; método geométrico; coração.

\section{Ciências modernas e tradição, ou: da ordem das ciências}

A reflexão pascaliana sobre o conhecimento move-se em direção a dois pontos de chegada: à legitimação do método das ciências modernas, enquanto ciências da natureza e das técnicas, e à sua ultrapassagem, buscando pensar um outro domínio de objetos, legalidades e formas de conhecimento. No Prefácio de Sobre o Tratado do vácuo, pequeno texto escrito em

1 Doutor em Filosofia e professor adjunto do Departamento de Filosofia da Universidade Estadual do Ceará (UECE). Artigo recebido em 08/08 e aprovado em 10/08. 
1651, o problema que Pascal se põe é justamente aquele acerca da necessidade de uma "ordem das ciências", cujo conteúdo consiste numa fundamental distinção entre as ciências da natureza e as ciências históricas. Com tal diferenciação, nosso autor busca defrontar-se duplamente - e é este confronto que alimenta e constitui o eixo de toda sua reflexão filosófica - com o advento das modernas ciências da natureza e com o problema teológico-religioso, com os assuntos relacionados à fé num momento histórico em que esta se torna problemática em razão justamente do nascimento das ciências modernas. Ainda que sua reflexão volte-se, nesse texto, para uma posição crítica da ortodoxia escolástico-tomista quanto às representações tradicionais do conhecimento da natureza, posição crítica que vem justamente em defesa da moderna pesquisa científica, ela não se volta menos criticamente, ainda que secundariamente aqui, para as tendências de absolutização ou universalização do método das ciências naturais sobre as matérias históricas (particularmente a religião e a moral). Em verdade, estes são dois erros que, segundo Pascal, devem ser evitados; e o podem se se considera justamente a "ordem" e a "diferença" das ciências.

Pascal constata criticamente na escolástica do século XVII um "respeito" à Antiguidade justamente em assuntos nos quais um tal respeito deveria ter "menos força". Os pensadores antigos ter-se-iam tornado "oráculos" em contraposição às "novidades". Nesta constatação crítica Pascal não pretende, contudo, simplesmente anular a "autoridade" dos antigos em nome dos raciocínios dos modernos, ainda que a reivindicação da autoridade pretenda, por parte da escolástica, torná-la única fonte possível do saber, em prejuízo precisamente do "raciocínio"; ao contrário, Pascal almeja, antes de tudo, propor uma distinção entre "autoridade" e "raciocínio":

É preciso considerar que umas [ciências] dependem apenas da memória e são puramente históricas, tendo por objeto de saber somente o que os autores escreveram; as outras dependem somente do raciocínio e são inteiramente dogmáticas, tendo por objeto procurar e descobrir as verdades escondidas. (Pascal, 1963a, p. 230)

A distinção aqui proposta assenta-se, pois, na identificação de dois planos não-comensuráveis, até mesmo paradoxais: um, aquele da autoridade, fundado na memória, constituinte das ciências históricas; outro, fundado no raciocínio, busca estabelecer conhecimentos "dogmáticos" acerca das "verdades escondidas". Esta "ordem das ciências", justamente por ter como visada o estabelecimento de métodos, ou, em seu próprio dizer, "direitos" distintos entre as ciências históricas e as ciências do raciocínio, tem também como objetivo delimitar o uso da "razão", constituindo seu campo próprio de legislação e atuação, assegurando - numa perspectiva que nos lembra Kant, mas certamente não é a deste autor - um lugar próprio para a 
fé. ${ }^{2}$ Em Pascal encontramos também centralmente, em sua proposição de uma "ordem das ciências", uma dupla crítica ao dogmatismo: ao dogmatismo que pretende pensar metafísica ou teologicamente a natureza, fechando-se para os métodos próprios das ciências modernas, fundadas no raciocínio; e ao novo, mais recente dogmatismo da razão, que pretende acriticamente estender seus direitos sobre as "matérias históricas". Sua afirmação de um conhecimento "dogmático", fundada no raciocínio, é, portanto, radicalmente antidogmatista e busca estabelecer estatutos próprios às duas classes de ciências implicadas em sua "ordem".

Essa distinção significa, num primeiro momento, aquela mais ampla existente entre a história, a geografia, a jurisprudência, as línguas e, sobretudo, a teologia, por um lado, e, por outro, a geometria, a aritmética, a música, a física, a medicina e a arquitetura, entre outras. Notemos que as ciências classificadas nesta última ordem são por demais diferentes entre si, mas todas elas, de maneiras diversas, têm em comum o uso ou do "raciocínio" ou da "experiência"; em geral, contudo, todas elas têm, de algum modo, uma matriz "matemática", "demonstrativa" ${ }^{3}$ Em sua extensão, portanto, a razão dessa distinção em duas classes de ciências - distinção que indica que o saber humano volta-se de modo distinto para os assuntos da natureza e das artes (técnicas), por um lado, e, por outro, para os assuntos históricos e moral-religiosos - deve-se a que, neste último agrupamento de saberes, diz Pascal (1963a, p. 230), "procura-se saber apenas o que os autores escreveram, donde é evidente que se pode ter dele o conhecimento completo, e que não é possível ajuntar-lhe nada". "O que os autores escreveram": é assim que Pascal define o sentido do termo "autoridade", definição que não podemos ler sem pressentir, nela, um certo ar irônico. A simplicidade quase ingênua com que Pascal exemplifica sua definição da autoridade como "o que os autores escreveram" tem como objetivo justamente delimitar duplamente o uso da "autoridade". Em primeiro lugar, ela constitui-se de um campo específico de saber, aquele no qual a apreensão

2 Por razão (raison) deve ser entendida a razão demonstrativa, tal como o século XVII, a partir de Descartes, compreende: trata-se do entendimento, espírito ou luz natural, cujo exemplo de uso mais adequado é a geometria. Não se trata aí, portanto, da razão tout court, mas daquele uso do pensamento que, no idealismo alemão, será chamado de entendimento (Verstand), em distinção da razão (Vernunft). As considerações pascalianas sobre a "razão" têm um caráter bem específico, aproximando-se daquele que será o esforço, próprio ao idealismo alemão, de delimitar o entendimento, faculdade de conhecimento da natureza, em vista da elaboração de um outro ponto de vista filosófico capaz de pensar os problemas morais, históricos, enfim, "sobrenaturais", como diz o próprio Pascal.

3 Chama a atenção a presença aí da medicina. Certamente valeria a pena considerar mais amplamente a experiência médica nesse período, mas, em princípio, não devemos esquecer que, enquanto corpo, o homem é concebido no século XVII, a partir de Descartes, como uma "máquina movente" e como um "autômato natural". Em alguns fragmentos dos Pensamentos, Pascal faz uso parcial de tais expressões para referir-se à existência corpórea do homem. 
das "matérias" ou "assuntos" depende do que foi estabelecido ou escrito por determinados autores, estando tais "matérias" ou "assuntos", neles próprios, a salvo de quaisquer desenvolvimentos, daí que não se lhes pode acrescentar algo "de novo" e, por isso mesmo, se pode ter deles um "conhecimento inteiro". Em segundo lugar, contudo, a autoridade, estando desse modo limitada, não pode ultrapassar aquilo que a constitui - mais uma vez, "o que os autores escreveram" - e se tornar obstáculo para o uso que, de modo legítimo, o raciocínio pode fazer de seus conhecimentos; e não pode porque, em verdade, à própria autoridade está obstaculizado imiscuir-se no âmbito de saber que, com legitimidade, cabe à razão e ao raciocínio. Este é uma dupla delimitação da autoridade, cuja contrapartida é uma também dupla delimitação da razão e do raciocínio: também estes não podem alterar ou se fazer substituir aos conhecimentos da autoridade, devendo bastar-se ao campo que lhes é próprio.

É no conjunto mais amplo dos conhecimentos históricos, cujo fundamento é a memória, que Pascal situa a teologia como um saber específico, a qual tem como objeto, diz ele, a "verdade". Justamente neste âmbito ele identifica um tipo de conhecimento cujas matérias são "as mais incompreensíveis à razão":

Seus princípios estão acima da natureza e da razão, o espírito do homem sendo muito fraco para aí chegar por seus próprios esforços, não pode alcançar essas altas inteligências se não é para aí levado por uma força todo-poderosa e sobrenatural. (1963a, p. 230)

Ora, em diferença com o que acontece nas ciências históricas (e, portanto, também na teologia, que nelas se inclui), nos assuntos concernentes à natureza e à razão natural, diz Pascal (1963a, p. 230), "a autoridade é aqui inútil, apenas a razão pode conhecer. Elas têm seus direitos separados: uma tinha mais cedo muitas vantagens; aqui a outra reina por sua vez". Precisamente considerando estas classes de ciências, que têm "direitos" e "reinos" distintos, leis e domínios próprios, decorre que, onde a razão, e não a auto-

4 Esta passagem é particularmente importante, pois nos antecipa, no interior mesmo da diferença entre os conhecimentos situados no nível da natureza e da razão natural e aqueles situados no da história e da memória, uma outra diferença central a toda a reflexão filosófica de Pascal: diferença que aqui se estabelece entre a razão, espírito ou entendimento, por um lado, e, por outro, digamos provisoriamente nestes termos, uma "força todo-poderosa e sobrenatural", cujos princípios estão "acima da natureza". Neste momento, contudo, nosso interesse volta-se ainda para aquela primeira diferença natureza/razão versus história/memória. Levando em conta esta primeira distinção, é importante também considerar que, se o conhecimento dos assuntos teológicos situa-se no âmbito dos conhecimentos históricos, não se identifica inteiramente com eles. Afinal, não há qualquer necessidade de uma "força todo-poderosa e sobrenatural" para saber quem foi o primeiro rei francês ou as palavras usadas numa língua morta... guardemos, pois, este problema - que constitui, na verdade, o objeto principal desta exposição - e continuemos a seguir a reflexão de Pascal sobre a "ordem das ciências". 
ridade, reina, os conhecimentos não são "limitados". Limitados são os conhecimentos da autoridade, "tanto quanto os livros em que eles estão contidos". Já nas ciências da natureza e das "artes", próprias à razão, esta "encontra uma liberdade toda inteira de aí se estender: sua fecundidade inesgotável produz continuamente, e suas invenções podem ser em seu conjunto sem fim e sem interrupção" (ibidem). Não é possível uma declaração mais "moderna" do que esta: a delimitação da autoridade aos assuntos históricos, a reivindicação da liberdade da razão ou do espírito nas ciências da natureza e das "artes", e, nestas, o caráter inesgotável e progressivo de nossos conhecimentos científicos.

O desenvolvimento dessas posições por Pascal guarda, como dissemos no início, uma dupla polêmica. A primeira permanece implícita e tem como interlocutor Descartes. Quanto a esta, basta lembrarmos, sucintamente, o que este filósofo diz no Discurso do método acerca de sua concepção de saber. Como é próprio ao modo de exposição desta obra, Descartes apresentanos no Discurso, na primeira pessoa do singular, uma experiência mais geral da modernidade com os saberes transmitidos do passado, os saberes tradicionais. Estes, sob as rubricas das "letras" - gramática, retórica, poesia e história -, se lhe apresentam incapazes de constituírem-se em ensinamento "seguro" e "certo", mas, ao contrário, conduzem a "dúvidas" e "erros", tendo como único proveito, nesta experiência que é a sua pessoal, mas que reflete uma posição moderna quanto ao ensino humanista clássico, o de permitir o reconhecimento da "ignorância". De modo parecido, a filosofia - e ele tem em vista aqui justamente a escolástica, a "filosofia da escola" - não consegue também chegar a qualquer conhecimento que não seja "disputável". E a teologia, é pelo menos o que diz no Discurso, só poderia constituir-se de "verdades reveladas" que "estão acima de nossa inteligência" e da "fraqueza de nossos raciocínios". Ora, essa posição crítica quanto aos saberes tradicionais - entre os quais recebe um estatuto provisoriamente distinto a teologia - expressa uma posição mais ampla e radical de Descartes quanto ao passado e à relação do presente com o passado. Segundo diz, baseado no fato de que seu século parece-lhe tão florescente quanto os anteriores, sua experiência o levou à conclusão da necessidade de, em suas palavras, "julgar por mim mesmo todos os outros séculos e de pensar que não existia doutrina no mundo que fosse tal como dantes me haviam feito esperar" (Descartes, 1979, p. 31). Em outra passagem, diz ainda que resolveu: "Não mais procurar outra ciência, além daquela que se poderia achar em mim próprio" (Descartes, 1979, p. 33). O significado disso é precisamente a pretensão de um afastamento - para utilizarmos aqui uma expressão que parece claramente em Pascal - da "autoridade":

aprender a não crer demasiado firmemente em nada do que me fora inculcado só pelo exemplo e o costume; e assim, pouco a pouco, livrei-me de muitos erros que podem ofuscar a nossa luz natural e nos tornar menos capazes de ouvir a razão. (ibidem) 
Em outras palavras, trata-se aqui do que ele mesmo nomeará depois, nas Meditações (I, 2), do gesto de "destruir em geral todas as minhas antigas opiniões" (Descartes, 1979, p. 85).

Embora aqui não possamos - nem seja nosso objetivo - traçar um confronto exaustivo entre as concepções de saber de Descartes e Pascal, convém, contudo, para melhor esclarecer o significado filosófico das posições deste último, notar algumas semelhanças e diferenças entre os dois. Em ambos, nota-se uma mesma postura de defesa das ciências modernas, enquanto ciências que não podem basear-se na autoridade e nos conhecimentos da tradição, mas sim apenas na "luz natural" e na "razão": como Descartes, Pascal entende ser necessária, no âmbito das ciências da natureza e das "artes", a recusa das "opiniões recebidas". Também quanto à teologia, ambos os autores afirmam que seus assuntos dependem das "verdades reveladas", que estão "acima da nossa inteligência" e da "fraqueza de nossos raciocínios". Com efeito, quanto à teologia, Pascal, no Prefácio de 1651, retoma quase literalmente aqueles termos que aparecem no Discurso de 1637: seus princípios estariam "acima" da razão, para eles nosso espírito é "fraco" .

No entanto, para além dessas semelhanças, uma primeira diferença pode ser identificada aqui, e se constitui da própria relação quanto ao "passado". Enquanto em Descartes apresenta-se uma postura muito mais radicalmente descontínua, de ruptura com o passado no método das ciências naturais - daí que ele fale em julgar por si mesmo "todos" os outros séculos, em "destruir" as antigas opiniões -, Pascal, mesmo partilhando do mesmo ponto de vista cartesiano quanto ao fundamento do "raciocínio" e, mais ainda, como veremos em Do espírito geométrico, quanto a ter este método como referência a "geometria", afirma uma noção de desenvolvimento contínuo das ciências da natureza e das "artes". Esta é uma visão muito mais histórica acerca do desenvolvimento dos conhecimentos naturais e técnicos do espírito humano; e não porque encontremos em Pascal um respeito acrítico ao passado, mas justamente porque este desenvolvimento constitui-se, no seu dizer, em "degraus" pelos quais as gerações presentes herdam, retomam, negam e vão adiante dos ensinamentos recebidos das gerações anteriores.

Se, no que diz respeito às ciências naturais e técnicas, Pascal já expressa uma posição muito mais histórica, em que uma certa continuidade mantém-se entre o presente e o passado, continuidade que, de resto, não nega momentos de ruptura, o mesmo ocorre, de modo ampliado, nos as-

5 A proximidade dessas suas posições filosóficas manifesta-se até mesmo no fato de o Prefácio e o Discurso serem apresentações a tratados científicos (no caso de Descartes, uma introdução a seus ensaios sobre meteoros, dióptrica e geometria). 
suntos e matérias da teologia. Como para Pascal, o próprio da razão é, para Descartes, o raciocínio, a demonstração, a prova, capazes de constituir um conhecimento seguro e certo. Que os três objetos da metafísica especial alma, mundo e Deus - possam ser objeto de "demonstração" é do que discorda Pascal, pois tal concepção expressa para ele justamente a face complementar da posição escolástica de extrapolar para as ciências da natureza e das "artes" o princípio de autoridade levado em conta nas ciências baseadas na memória. A rigor, para Descartes não seria nem mesmo possível - dada a extensão que promove do método da demonstração ao conjunto das ciências e, portanto, ao próprio critério de cientificidade - conceber a existência de ciências baseadas na memória. A determinação da memória - comum às "letras", às quais ele se refere no Discurso - não se constitui de qualquer relação necessária e, portanto, não satisfaz a exigência do método de clareza e distinção. A Regra II das Regras para a direção do espírito define a ciência justamente como "cognição certa e evidente", recusando como tal tudo o que é "somente provável" e, portanto, aceitando apenas o que "é perfeitamente conhecido e de que não se pode duvidar" (Descartes, 1989, p. 14). De resto, é este o critério que já aparece no Discurso e nas Meditações. Trata-se, em todas essas passagens, da exigência de pensar por princípios, unicamente a partir dos quais a certeza, a clareza e a evidência podem estabelecer-se como critérios de verdade. Ora, a memória e as disciplinas a ela ligadas não podem conferir essa relação necessária, evidente e certa. Para Descartes, portanto, a memória, porque falível, incerta e insegura, não poderia, como pretende Pascal, constituir base para uma classe de ciências. Ao contrário, segundo as Regras, III, os "exercícios" e "disciplinas" caracterizam-se justamente pela incerteza, diferentemente do que ocorre com a matemática e, mais amplamente, com o "método dos geômetras", que nos ordena partir apenas daquilo que se manifeste evidente à razão (intuição), inferir daí proposições outras segundo uma ordem do simples ao composto, sem nada precipitar ou avançar que não seja permitido pelas anteriores proposições evidentes (dedução) (Descartes, 1989, p. 18-22).

Não resta dúvida, contudo, de que a diferença entre as ciências da memória e as ciências do raciocínio propostas por Pascal em classes distintas na "ordem das ciências" é devedora dessa distinção crítica de Descartes. ${ }^{6}$ A diferença para com Descartes e a distinção do método do raciocínio com um outro capaz de fornecer a inteligibilidade dos objetos "sobrenaturais" (históricos, morais etc.) só podem acontecer em Pascal com base na legitimação

6 Em seu artigo "O conhecimento em Pascal", Oliva (2004, p. 111 et seq.) apresenta uma interpretação que, buscando delinear os pontos de ruptura de Pascal com Descartes, secundariza este elemento que, a nosso ver, é central para uma justa compreensão da posição pascaliana diante do conhecimento: o ponto de partida comum aos dois pensadores no método das ciências modernas, enquanto método à maneira dos geômetras, posição filosófica que expressa, em ambos, a legitimação da prática científica moderna de compreensão matemática da natureza. 
do próprio método do raciocínio e da afirmação da evidência como critério da verdade neste âmbito. O que é próprio a Pascal nesse domínio é o esforço por mostrar que o método do raciocínio e da demonstração encontra em si mesmo seus limites, donde ele transita, com base em tais limites, a um outro modo de conhecimento, radicalmente distinto, que é o conhecimento imediato do "coração". Portanto, trata-se de uma dívida para com o pensamento cartesiano que procura precisamente limitar o âmbito das ciências do raciocínio, buscando estabelecer o "direito" e o "reino" próprios às ciências da memória e da autoridade. É neste sentido que a crítica da escolástica e de sua exigência da autoridade nos conhecimentos da natureza, crítica comum a Descartes e Pascal, significa também, neste último, a crítica do projeto cartesiano de extensão (para Pascal, extrapolação) do método das ciências da razão à condição de critério de todo conhecimento possível.

\section{Dos limites da geometria, ou: dos limites da razão}

A distinção entre as ciências do raciocínio e as da memória não se faz em Pascal apenas no sentido de uma delimitação exterior do método das ciências do raciocínio. Embora elas sejam paradoxais, pois situadas em duas ordens com domínios e direitos distintos, a demarcação das ciências históricas e da autoridade com relação às do raciocínio e da natureza ocorre em Pascal com base numa exposição dos próprios limites dessas últimas. Deste modo, em Do espírito geométrico, escrito provavelmente entre 1657-8, Pascal tem um duplo objetivo: expor tanto as potencialidades da razão, que se expressam em seu uso "geométrico", quanto seus limites, que se demonstram pelo fato de que seus princípios lhe escapam. Identificando razão e geometria, enquanto ambas são, respectivamente, a faculdade e o facultado por excelência do e ao homem, Pascal busca demonstrar, ao mesmo tempo, suas possibilidades e seus limites.

Se a razão humana procede "geometricamente", pois unicamente deste modo ela conhece e demonstra o que está a seu alcance conhecer e demonstrar, a este modo é imanente um ideal perfeito de conhecimento e demonstração que, enquanto imanente a (e, portanto, implícito em) seu uso possível, não está, contudo, ao alcance da razão fazer-lhe uso. Este modo ideal pressuposto em toda demonstração possível, porque é vetada à razão sua realização, demonstra precisamente assim o limite desta justamente no que lhe é mais alta e propriamente facultado. De maneira simples, trata-se aqui da impossibilidade da razão, em seu método demonstrativo, de definir e demonstrar - exigência do próprio método geométrico - todos os termos e proposições em que se baseiam, respectivamente, suas proposições e demonstrações ulteriores. 
Desse modo, longe de uma crítica - isto é, de um julgamento - exterior, cujo fim seria descartar a razão e seu procedimento geométrico, a crítica de Pascal desenvolve-se de modo imanente à própria razão geométrica, com base nas próprias exigências desta, utilizando-se, portanto, de seus raciocínios, com o objetivo de indicar que, exatamente ali onde se encontram suas maiores potencialidades e possibilidades de conhecimento, encontram-se na mesma medida seus limites, sendo estes limites que a capacitam a conhecer e demonstrar de modo verdadeiro. Em outras palavras, tais limites - a impossibilidade de definir todos os termos e de demonstrar todas as proposições de que se serve, justamente quando seu procedimento exige a definição e a demonstração - constituem, de modo inseparável, a própria capacidade da razão de demonstrar o que pode ser demonstrado. É por não definir e demonstrar todas as coisas, excluindo de suas exigências as que não podem ser definidas e demonstradas, que a razão, em seu procedimento geométrico, pode definir e demonstrar com acerto o que está a seu alcan$\mathrm{ce}$, donde justamente sua potencialidade positiva enquanto faculdade de conhecimento humana. Mas também daí advém, segundo o uso possível da própria razão, o seu limite que é, por ela mesma, reconhecível; é este reconhecimento o que constitui a potencialidade negativa da razão de ir além de si mesma, ou melhor, de saber-se limitada e, ao assim saber-se, abrir-se para sua própria ultrapassagem.

O estudo da verdade, segundo Pascal, apresenta-se sob três modos: o da descoberta da verdade, o da sua demonstração, quando já se a encontrou, e seu discernimento do falso. Esses três modos constituem, diz ele, "o método que a geometria observa", arte ou método que consiste em provar ou demonstrar cada proposição e em dispor a totalidade delas numa ordem. Em outras palavras, essa é "a conduta do raciocínio para provar e definir as verdades" (Pascal, 1963b, p. 349). O primeiro desses modos, que trata da descoberta da verdade, dá-se pela análise. A este respeito, Pascal (1963b, p. 348) nada discorre, limitando-se a observar que, sobre este assunto, há "tantas excelentes obras". ${ }^{7}$ Escusando-se da tarefa - que, aparentemente,

7 Na falta de uma exposição do modo analítico, pelo próprio Pascal, recorramos a Descartes. Na resposta à Segundas objeções apresentadas por Pierre Mersenne às suas Meditações, Descartes, que reivindica ter usado a análise nesta obra, distingue, no método dos geômetras - que, assim como diz Pascal, consistiria em ordem e demonstração -, as "maneiras" sintética e analítica de demonstração. Esta última, diz ele, "mostra o verdadeiro caminho pelo qual uma coisa foi metodicamente descoberta e revela como os efeitos dependem das causas". Já a maneira sintética, "ao contrário, por um caminho todo diverso, e como que examinando as causas por seus efeitos (embora a prova que contém seja amiúde também os efeitos pelas causas), demonstra, na verdade, claramente o que está contido em suas conclusões, e serve-se de uma longa série de definições, postulados, axiomas, teoremas e problemas, para que, caso lhe neguem algumas consequências, mostre como elas se contêm nos antecedentes, de modo a arrancar o consentimento do leitor, por mais 
Descartes realizou em sua resposta às segundas objeções apresentadas por P. Marsenne -, Pascal propõe-se a esclarecer a demonstração sintética, ${ }^{8}$ que, segundo diz, encerra o discernimento da verdade com relação ao falso. Já de entrada, Pascal (1963b, p. 349) observa, contudo, que, para explicar perfeitamente a conduta das demonstrações, é preciso de antemão a "ideia" (idée) de um método ainda mais "eminente" e "desenvolvido" (accompli), ao qual "os homens não poderiam jamais chegar: pois o que vai além [passe] da geometria nos ultrapassa [surpasse]". Em outras palavras: a) o método geométrico das demonstrações pressupõe um outro, mais completo e eminente; b) o que é próprio do raciocínio é a conduta geométrica, enquanto análise, demonstração e discernimento do falso; e c) o que está para além do geométrico, como é o caso deste método mais perfeito e completo que o geométrico implica, também está além de nós enquanto seres racionais (rationels), capazes de raciocínios. Tais afirmações poderiam ser ordenadas numa série dedutiva do tipo: o que está para além do método geométrico também está para além da razão; o método mais perfeito e realizado, pressuposto no método geométrico, ultrapassa as possibilidades deste; logo, o método mais perfeito e realizado, pressuposto no método geométrico, ultrapassa as possibilidades da razão.

Por ir além do método da geometria, tal método ali pressuposto nos ultrapassa. Ele é, pois, impossível de ser praticado e, até mesmo, de reunir-se às demonstrações possíveis. É seu uso pela geometria que, contudo, ao implicá-lo, e apesar de não o alcançar, permite-nos pensar este método fundamental, pois, segundo Pascal (1963 b, p. 349), "apenas ela [a geometria] sabe as verdadeiras regras do raciocínio [...] e se funda no verdadeiro método de conduzir o raciocínio em todas as coisas". Deste modo, Pascal só pode dizer-nos o que é a demonstração, tomando como exemplo as da geometria, quase a única ciência a produzi-las de modo correto e a única a observar o

obstinado e opiniático que seja [...]". O uso, nas Meditações, da maneira analítica do método geométrico justificar-se-ia, para Descartes, porque, "se o leitor quiser segui-la e lançar cuidadosamente os olhos sobre tudo o que contém, não entenderá menos perfeitamente a coisa assim demonstrada e não a tornará menos sua do que se ele próprio a houvesse descoberto". Já o método sintético tem - para os objetivos das Meditações - o inconveniente de que "não dá, como a outra, inteira satisfação aos espíritos dos que desejam aprender, porque não ensina o método pelo qual a coisa foi descoberta" (grifos nossos). Mais do que concernente aos objetivos de ensino das $\mathrm{Me}$ ditações, Descartes, contudo, justifica ainda - e talvez seja esta justificativa mais importante que a síntese "não convém [...] tão bem às matérias que pertencem à metafísica", pois, nestas, "a principal dificuldade é conceber clara e distintamente as noções primeiras" (cf. Descartes, 1979, p. 166-7). Para exposições mais amplas do método analítico em Descartes, cf. Landim Filho (1992, especialmente p. 28-9) e Battisti (2002, especialmente p. 341-84).

8 O próprio Pascal não nomeia assim essa maneira do método geométrico; fazemo-lo aqui, em termos cartesianos, por exclusão da "análise", que, assim como também diz Descartes, serve para a "descoberta" da verdade. 
"verdadeiro método". Em outras palavras, é unicamente pela geometria, na medida em que ela observa de modo exemplar e tanto quanto lhe é possível as exigências da demonstração, que se pode pensar - ainda que não realizar completamente - o verdadeiro método em sua perfeição. É a própria impossibilidade de sua realização completa pela geometria, ciência que a realiza o mais proximamente quanto é possível, que apresenta ao pensamento a ideia do método verdadeiro e perfeito, e justamente porque a geometria não o pode realizá-lo, mas apenas o pressupor. O que é, pois, este "verdadeiro método" do qual Pascal pretende oferecer uma ideia, antes de explicar a demonstração pelo exemplo da geometria? Vejamos:

Este verdadeiro método, que formaria as demonstrações na mais alta excelência, se fosse possível a ela chegar, consistiria em duas coisas: uma, não usar nenhum termo do qual não se explicou antes claramente o sentido; outra, não avançar nunca nenhuma proposição que não se demonstrou com base em verdades já conhecidas; isto é, numa palavra, em definir todos os termos e provar todas as proposições. (Pascal, 1963b, p. 349)

O que se entende, pois, por definição? Responder a esta pergunta é satisfazer uma exigência do próprio método agora anunciada. Trata-se aqui de uma definição de nome, o que quer dizer, em geometria, a imposição de nomes às coisas em termos perfeitamente conhecidos. A definição de nome abrevia a definição, o que, de qualquer modo, exigiria a cada vez o uso de vários termos. Além disso, o nome imposto deve estar livre de qualquer ambiguidade, de "todo outro sentido". Assim, para evitar confusões ou ambiguidades, ao lermos ou construirmos uma definição, que é sempre composta de vários termos, deve-se ter no espírito uma definição pronta a substituir o definido. Na definição "X é y de q", deve-se ter em mente as definições de y e de $q$, de modo que a definição de $X$ seja-nos clara, sem confusões ou ambiguidades. O método verdadeiro consistiria, pois, em definir todos os termos e em provar todas as proposições. Mas, assim concebido, este método torna-se impossível - embora seja o mais verdadeiro -, pois, segundo Pascal (1963b, p. 349),

É evidente que os primeiros termos que se quereria definir, deles se suporiam precedentes para servir à sua explicação, e que, do mesmo modo, as primeiras proposições que se quereria provar delas se suporiam outras que as precedessem; e assim é claro que não se chegaria às primeiras.

Em outras palavras, Pascal retoma aqui, para também recusá-lo, o "regresso infinito" de que já nos falara Aristóteles na Metafísica, e o faz com o objetivo de dizer-nos que os princípios dos raciocínios escapam à própria razão. Numa definição, regredindo - ou, se se quiser, avançando a pesquisa - chega-se a "palavras primitivas que não se pode mais definir, e a princípios tão claros que deles não se encontra [outros] mais que sirvam à sua prova" (Pascal, 1963b, p. 350). 
Ainda que seja, contudo, impossível ao homem responder positivamente às exigências de uma ordem perfeita e realizada (isto é, tudo definir e tudo demonstrar), Pascal não conclui daí que se deva abandonar todo tipo de ordem. A geometria, constituindo uma verdade inferior, não é, todavia, menos certa. Nem define nem prova tudo, mas sim supõe apenas o que é claro e constante para a luz natural e, nisto mesmo, é verdadeira. Afinal, nesta impossibilidade de tudo definir e tudo provar, encontra-se um limite da própria razão, limite este que supõe o que lhe é claro e constante, não podendo, porém, definir e demonstrar o que lhe serve de fundamento para as definições e demonstrações que estão a seu alcance realizar. Deste modo, no método usado pela geometria, método que Pascal considera "o mais perfeito entre os homens", se busca "manter-se neste meio de não definir as coisas claras e entendidas por todos os homens, e definir todas as outras, e de não provar todas as coisas conhecidas por todos os homens, e provar todas as outras" (Pascal, 1963b, p. 350).

Mas o que a geometria não define e que, contudo, lhe serve de base? $\mathrm{O}$ espaço, o tempo, o movimento, o número, a igualdade, termos estes todos tão naturalmente claros ao espírito, que a busca de seu esclarecimento só conduziria a obscuridades. Ora, aqui já estamos diante do problema do conceito pascaliano de "coração" (cœur), como podemos ver no fr. B. 282; L. 110, dos Pensamentos: ${ }^{9}$

Conhecemos a verdade não apenas pela razão [raison], mas também pelo coração [cœur]. É desta última maneira que conhecemos os primeiros princípios, e é em vão que o raciocínio [raisonnement], que não toma parte nisso, tenta combatê-los. [...] Pois os conhecimentos dos primeiros princípios: espaço, tempo, movimento, números, são tão firmes quanto qualquer daqueles que os nossos raciocínios nos dão e é somente sobre esses conhecimentos do coração e do instinto [instinct] que é necessário que a razão se apoie e fundamente todo seu discurso. O coração sente que existem três dimensões no espaço e que os números são infinitos, e a razão demonstra depois que não existem dois números quadrados dos quais um seja o dobro do outro. Os princípios se sentem, as proposições se concluem, e tudo com certeza, embora por diferentes caminhos [...].

Tais princípios da razão, não apenas não se os define, mas são eles mesmos indefiníveis na medida em que a definição, assim como a demonstração, compõe o método próprio à razão e ao raciocínio. Desses termos temos naturalmente uma ideia que não podemos exprimir; essa ideia é mais segura e mais clara que qualquer outra que uma explicação da razão dela poderia nos dar. Na verdade, esses termos primitivos - diríamos hoje, esses

9 As referências bibliográficas dos fragmentos dos Pensamentos serão citadas, entre parênteses, no próprio corpo do texto, antecedidos das iniciais B., para a edição Brunschwicg (Pascal, 1999) e L., para a edição Lafuma (Pascal, 1963; 2001). 
princípios "linguísticos" de todo raciocínio - são indefiníveis pelo raciocínio justamente porque são seus princípios, logo, fundamento de toda definição e de toda demonstração. A que se deve, no entanto, que essas palavras, não passíveis de definição, pois lhes são implícitas, sejam "naturalmente" claras aos homens? Em Do espírito geométrico, diferentemente do que ocorre nos Pensamentos, nas quais ele o debita ao "coração", Pascal responde a esta pergunta recorrendo ao conceito de "natureza" (nature): esta teria dado a todos os homens uma "ideia semelhante, igual" (idée pareille) desses termos; deles, ela nos teria dado, "sem palavras, uma inteligência mais clara que aquela que a arte adquire por nossas explicações" (Pascal, 1963b, p. 350). Esta ideia comum a todos os homens acerca desses termos não os constitui, contudo, em "ideias inatas", no sentido cartesiano, pois não se trata de que todos os homens tenham as mesmas ideias das eSsências desses termos - o que já seria uma definição de essência inata, como ocorre na ideia de Deus em Descartes -, pois, ao contrário, há disputas quanto às suas essências, quanto ao que elas são. O que nos ocorre "naturalmente" no espírito quanto a esses termos não é uma definição de essência (ou de coisa ou de natureza) a que se referem esses termos, mas uma definição de nome, isto é, uma compreensão imediata da relação de designação entre o nome e a coisa designada. "De modo que por essa expressão, tempo", diz Pascal (1963, p. 350), "todos levam o pensamento em direção à mesma coisa" - sem que, contudo, tenhamos naturalmente desta coisa a mesma definição de essência.

O fundamental para entendermos o que Pascal está nos dizendo, com o objetivo de demonstrar a indefinibilidade de determinados termos primitivos e, portanto, os limites da razão quanto a seus próprios princípios de definição e demonstração, é compreender a distinção entre definição de nome e definição de essência (ou de coisa ou de natureza). À escuta da palavra "tempo" todos dirigem seu pensamento em direção ao mesmo objeto, sem que com isso se dirijam para a mesma essência ou à mesma natureza dessa coisa. A definição de nome, a qual Pascal diz ser necessário estabelecer e a qual não é possível ser estabelecida de todos os termos, constitui-se exclusivamente da relação nome-coisa e não da relação coisa-essência/natureza. A pergunta a que coisa se dirige a palavra "tempo"?, imediatamente compreendida de modo igual por todos, distingue-se, pois, da pergunta o que é o tempo? Deste modo, os nomes primitivos, ainda que não sejam definíveis, remetem-nos às coisas; e não nos remetem às essências/naturezas das coisas. O que se faz imediatamente presente no espírito mediante esses nomes não é a definição essencial, como nos casos em que os termos são definidos, mas sim as coisas ou objetos; sabemos o que estamos nomeando ou sabemos a que estamos nos referindo com os nomes, as coisas que estamos designando, mas não sua quididade. 
As tentativas de definição de nome daquelas coisas que são claras ao espírito criam necessariamente equívocos, pois, ao que todos entendem natural e imediatamente pela palavra primitiva (a relação entre o nome e a coisa), acrescenta-se a definição da coisa ali nomeada. Assim, em consequência, enquanto definição de nome cria-se, com isso, um equívoco; enquanto definição de coisa nada se diz, pois esta não se determina pela confusão de duas coisas num mesmo nome (sinônimos). Quando o geômetra renuncia a dar uma definição de nome a uma palavra primitiva, ele se livra da confusão seja entre definição de nome e definição de coisa (o que seria, então, uma proposição a ser demonstrada), seja entre definição de coisa e axioma (um princípio indemonstrável). Com a exclusão dos termos primitivos, todos os outros termos que são passíveis de definição são definidos e esclarecidos. Donde temos que todos os termos presentes nas demonstrações geométricas são inteligíveis ou pelas definições ou pela luz natural. O mesmo ocorre quanto às demonstrações das proposições. Tratase, na geometria, de demonstrar todas, menos aquelas que são claras por si mesmas (axiomas), de modo que, assim como ocorre com as definições, todas as proposições ou são demonstradas ou são claras por si mesmas.

\section{Do cœur, ou: do "estudo do homem"}

Mas o que significa filosoficamente este limite das definições e das demonstrações? Para Pascal, este é o limite "humano", ou melhor, da razão e de sua atividade, o raciocínio. A geometria não pode definir nenhum de seus princípios (ou termos principais) - espaço, tempo, movimento, número -, dos quais decorrem os objetos de suas espécies: geometria (em gênero e espécie), mecânica e aritmética. Ainda que desses termos ela não tenha definições e de determinadas proposições ela não tenha demonstrações, pois são claras ao espírito, delas a geometria tem, no entanto, toda a "certeza" (certitude). Em outras palavras, a incapacidade da razão e do raciocínio de definir esses termos mais simples constitui-se mais numa perfeição do que num defeito, e esta perfeição está em que, deste modo, se pode chegar a um conhecimento certo, porque se parte do que é evidente ao espírito. No limite da compreensão imediata da coisa à qual o nome corresponde, evitam-se a desnecessária definição de nome e a impossível definição de coisa/natureza, o que não impede, contudo, que o entendimento humano possa chegar a conhecer algumas "propriedades" (propriétés) de sua "natureza" (nature).

Pode compreender-se, assim, que o movimento implica espaço e tempo; que a compreensão do tempo, do espaço e do movimento implica o número, e assim por diante. Mais ainda: compreendem-se propriedades comuns a todas essas coisas, e delas a fundamental é - para a questão aqui em discussão - sua natureza duplamente infinita. Todo movimento pode ser acrescentado ou diminuído infinitamente, assim ocorrendo também com o 
número, o espaço, o tempo: pode-se infinitamente multiplicá-los, e infinitamente dividi-los. Também aqui se trata de conhecimentos acerca de propriedades da natureza dessas coisas que, contudo, não podem ser "demonstrados", mas que - ou justamente porque - são "evidentes" e "certos" ao espírito. "Daí que", conclui Pascal (1963b, p. 352),

se vê que a geometria não pode definir os objetos nem provar os princípios; mas por uma única e vantajosa razão, que uns e outros estão numa extrema clareza natural, que convence a razão mais poderosamente que o discurso.

À evidência, é preciso ainda acrescentar um outro princípio da demonstração: trata-se precisamente do exame da verdade de uma proposição pela falsificação de seu contrário. Deste modo é que se demonstra a contrario a divisibilidade infinita do espaço, do tempo, do número, mesmo que não se possa com propriedade e rigor demonstrá-la positivamente. E assim é porque, diz Pascal, "esses dois contrários sendo todos os dois inconcebíveis, é entretanto necessariamente certo que um dos dois é verdadeiro". ${ }^{10}$ Em suma, nesses dois princípios da demonstração, que obedecem ambos ao princípio de identidade, expressa-se a conduta da razão, cujas regras básicas Pascal resume em $A$ arte de persuadir. Apresentam-se aí, contudo, também dois problemas maiores. Para Pascal, o conhecimento da natureza duplamente infinita do espaço, do tempo e do número remete, no plano ético, à concepção antropológica sobre o posicionamento do homem entre duas infinitudes. Trata-se aí da necessidade, para os homens, de

aprenderem por esta consideração maravilhosa [da dupla infinitude do espaço, do tempo e do número] a se conhecerem a si mesmos, olhando-se localizados entre uma infinitude e um nada de número, entre uma infinitude e um nada de movimento, entre uma infinitude e um nada de tempo. Sobre o que se pode aprender e estimar em seu justo preço, e formar reflexões que valem mais que todo o resto da geometria. (Pascal, 1963b, p. 355)

Neste autoconhecimento do homem, que, no saber racional sobre a dupla infinitude das realidades matemáticas e físicas, pode encontrar uma imagem da dupla infinitude entre as quais, metafisicamente, ele se situa, é que se posiciona a distinção entre a razão demonstrativa e o que Pascal chama metaforicamente de "coração". Pascal apresenta-a levando em consideração toda sua discussão sobre os limites da razão e o desconhecimento pela razão de seus próprios princípios, donde, portanto, justamente por isso, se pode chegar à conclusão de que há uma instância anterior e superior à própria razão que é capaz de persuadi-la, pois lhe oferece seus princípios;

10 Idem, p. 353 
uma instância que persuade a alma de um modo não-demonstrativo, eo ipso, não-"racional". Não a nomeando de "coração", mas de "vontade", Pascal (1963c, p. 355) apresenta-a - em A arte de persuadir - primeiramente do seguinte modo:

Ninguém ignora que há duas entradas por onde as opiniões são recebidas na alma, que são suas duas principais potências, o entendimento e a vontade. A mais natural é aquela do entendimento, pois somente se deveria consentir às verdades demonstradas; mas a mais ordinária, ainda que não natural, é aquela da vontade, pois todos os homens são quase sempre levados a crer não pela prova, mas pelo agrado.

Em seguida, a mesma distinção anímica é novamente elaborada, mas, desta feita, à "vontade" substitui o "coração" e, às "opiniões", substituem as "verdades":

Eu somente falo de verdades de nosso alcance; e é delas que digo que o espírito e o coração são como as portas por onde elas são recebidas na alma, mas que bem poucas entram pelo espírito, enquanto elas aí são introduzidas em multidão pelos caprichos temerários da vontade, sem o conselho do raciocínio. (Pascal, 1963c, p. 355)

Esses são dois problemas que estão intimamente ligados: o tipo de conhecimento que é próprio ao "coração" e o tipo de conhecimento que podemos ter do homem. Deste modo, o problema do conhecimento, para Pascal, reenvia-nos para um problema mais amplo: o antropológico. ${ }^{11}$ A tematização do conhecimento conduz-nos ao âmbito antropológico, porque, em primeiro lugar, conforme vimos nos Pensamentos, Pascal situa os princípios da razão e do raciocínio no "coração"; em segundo lugar, como podemos ver

11 Há que se considerar aqui que a remissão do problema do conhecimento ao âmbito antropológico não se identifica à remissão kantiana ao transcendental, embora ambos os pensadores tenham a preocupação com as possibilidades e a limitação do conhecimento da natureza (a matemática e a física), sendo tal preocupação tematizada com base numa perspectiva antropológica. Conforme diz M. A. Oliveira, antes de tudo, "a antropologia é em Kant não um objeto de consideração, mas o horizonte a partir de onde e em relação ao qual tudo pode ser pensado. [...] É importante notar que neste nível se faz a verdadeira reflexão de ordem filosófica sobre o homem: é retornando transcendentalmente à subjetividade finita como sujeito de conhecimento e ação que se tematiza o conjunto de condições possibilitantes do conhecimento e da ação e, com isto, indiretamente, se diz o que é o homem. [ף] Mas ao lado desta reflexão transcendental sobre o homem, há uma consideração de ordem empírica (sobre o homem) que recebeu, propriamente, o nome de antropologia" (Oliveira, M. A. "Antropologia na filosofia de Kant". A filosofia na crise da modernidade. São Paulo: Loyola, 1989, p. 15). Em Pascal, o conhecimento é pensado num âmbito antropológico nãoempírico, embora não transcendental no sentido kantiano: é, pois, como discutiremos a seguir, no âmbito de uma doutrina antropológica sobre-empírica, metafísica, das três "ordens" nas quais o homem se situa e das quais ele se constitui. 
em $A$ arte de persuadir, texto que segue imediatamente a Do espírito geométrico, o raciocínio não é a única fonte da persuasão, já que as opiniões entram na alma tanto pelo entendimento quanto pela vontade; ou, ainda, as verdades são recebidas na alma tanto pelo espírito quanto pelo coração.

Aqui, mais uma vez, há um debate com Descartes. Este, nas Meditações, IV, 10, propõe uma diferença entre o entendimento (faculdade de conceber) e a vontade (poder de escolha, arbítrio). Para Descartes, os erros humanos têm origem em que,

sendo a vontade muito mais ampla e extensa que o entendimento, eu não a contenho nos mesmos limites, mas estendo-a também às coisas que não entendo; das quais, sendo a vontade por si indiferente, ela se perde muito facilmente e escolhe 0 mal pelo bem ou o falso pelo verdadeiro. O que faz com que eu me engane e peque. (Descartes, 1979, p. 119)

A origem do erro não estaria, assim, nem no entendimento nem na vontade, enquanto faculdades anímicas, mas antes na diferença entre a faculdade de conceber, "de uma extensão muito pequena e grandemente limitada", e a vontade, "que eu sinto ser em mim tão grande, que não concebo absolutamente a ideia de nenhuma outra ampla e mais extensa" (ibidem). Para Descartes, a correção intelectual estaria, pois, em a vontade só afirmar ou negar conforme o que é claro e distinto (portanto, verdadeiro) para o entendimento; e a correção moral, em querer (ou perseguir) e recusar (ou fugir) baseado no que concebe o entendimento. Em outras palavras, deve-se basear a vontade no entendimento (para bem julgar) e salvaguardar o entendimento da ilimitação da vontade (para bem conceber em assuntos teóricos). ${ }^{12}$

12 Sobre esta teoria cartesiana das faculdades anímicas e seu concurso na origem de nossos erros, diz Forlin (2005, p. 1-2): "O que está em jogo, portanto, é a relação entre a faculdade de perceber e conectar ideias - ou seja, o entendimento - e a faculdade de fazer juízos, isto é, de julgar o valor de verdade das ideias assim percebidas e conectadas pelo entendimento - ou seja, a vontade [Med., II, § 4]. Como ficou estabelecido na Meditação terceira, o critério de verdade de uma ideia é a clareza e a distinção: tudo aquilo que for percebido clara e distintamente pelo entendimento é verdadeiro. Esta própria regra é ela um juízo verdadeiro que a vontade produziu espontaneamente sobre a percepção de que o entendimento tem de sua própria operação de perceber [Med., III, § 2]. Desta forma, sendo a própria regra de verdade um juízo universal, então podemos concluir que, sempre que a faculdade da vontade julgar de acordo com aquilo que o entendimento percebe clara e distintamente, ela produzirá um juízo verdadeiro. O erro, em contrapartida, surge sempre que a vontade não proceder assim. O que significa: sempre que a vontade produzir um juízo sobre o valor de verdade daquilo que o entendimento não percebe clara e distintamente ou para além do que ele percebe clara e distintamente". Segundo esta leitura, não há dúvida de que a faculdade da vontade, enquanto faculdade de produzir juízos a despeito do critério de clareza e distinção, mantém a liberdade do arbítrio em face das concepções/percepções do entendimento. É este arbítrio da vontade que aqui interessa a Pascal, em sua busca de pensar para além do procedimento demonstrativo da razão. 
Não há dúvida, Pascal parte desta distinção cartesiana. Não a questiona ou critica, mas dela retira outra conclusão: que a vontade seja mais ampla que o entendimento e que, com base em sua amplitude, ela afirme ou negue, queira ou recuse o que não é evidente para o entendimento, isto não conduz necessariamente a erros teóricos ou morais. Antes, Pascal vê aí a abertura de outra "entrada" ou "porta" na alma para opiniões ou verdades. Deste modo, já em $A$ arte de persuadir ele se refere a uma outra instância de opinião (a vontade) ou de verdade (o "coração"), que não o entendimento (razão ou espírito). Ao referir-se à vontade ou ao "coração" como porta ou entrada de opiniões e verdades na alma, com isto retirando o monopólio ao entendimento (ou razão), $A$ arte de persuadir encontra-se com o que, nos Pensamentos, diz Pascal: "Conhecemos a verdade não só pela razão [raison], mas também pelo coração [cœur]" (B. 282; L. 110). ${ }^{13}$

A questão, sem dúvida alguma central para o problema do conhecimento em Pascal, é, portanto, em primeiro lugar, a relação entre a vontade e o que ele chama metaforicamente de "coração". Naturalmente, a resposta à questão tem como centro a própria concepção pascaliana do "coração". Justamente por isso, como afirmamos no início deste tópico, toda a questão do conhecimento para Pascal situa-se no plano antropológico. Ora, o que há de fundamental na retomada que fazemos de Do espírito geométrico e A arte de persuadir é que, nesses textos, Pascal discute um duplo limite da razão. Primeiramente, um limite interno, no sentido da incapacidade da razão, segundo seus critérios de definição e demonstração, de realizar suas próprias exigências; neste caso, tais princípios são devidos à ordem do "Coração", que conhece a verdade de um modo não-demonstrativo, não discursivo, logo, intuitivo. Secundariamente, um limite externo, ainda que no interior da própria alma: a razão ou entendimento não é o único móvel da persuasão, pois ao convencimento demonstrativo do espírito se opõe, não raras vezes, a opinião da vontade, que cede ao que é agradável, assim como a verdade do "coração" distingue-se da demonstração racional. Esta dupla limitação do entendimento leva-nos ao centro da antropologia pascaliana: a sua doutrina das três ordens.

13 Diante das teorias cartesianas do erro e do livre-arbítrio da vontade, Pascal procede de um outro modo do efetuado por Espinosa. Este considera um engano esta distinção cartesiana entre entendimento e vontade, enquanto faculdades distintas, pois não haveria no homem uma faculdade específica do querer (a vontade), mas apenas volições particulares que são somente, elas mesmas, formas de pensamento; donde a conclusão de que toda a questão do querer e do agir é imediatamente idêntica à do conhecer, não podendo ser a vontade "causa desta ou daquela volição" (Espinosa, 1983, p. 367-8). Assumindo a existência de duas faculdades anímicas distintas, Pascal vê na vontade (à qual identifica também o coração) uma forma de persuasão, uma fonte de opinião, que indica uma outra forma de conhecimento que não o conhecimento demonstrativo da razão. 
Diz-nos o fr. B. 283; L. 298: "O coração tem sua ordem, o espírito tem sua ordem, por meio de princípios e demonstrações; o coração tem outra". Deste modo, à distinção cartesiana entre a res cogitans e a res extensa, Pascal acrescenta a concepção de que o homem pertence simultaneamente também a uma terceira ordem: o "coração". ${ }^{14}$ Enquanto ordens distintas, o corpo, o espírito (ou razão) e o "coração" têm suas razões distintas. É por isso que, se, na razão, a persuasão ocorre graças ao convencimento por demonstrações e provas, no "coração" a verdade persuade por uma imediatidade do "sentir" ou por um "conhecimento" que é imediato, intuitivo; do mesmo modo, se o espírito tudo define e demonstra, há, contudo, verdades que, "sentidos", conhecidos imediatamente pelo "coração" oferecem-se à razão como princípios dela. Trata-se aí, insistimos, de duas "ordens" com alcances, domínios, leis diferentes. A mesma distinção se dá com relação ao corpo. Assim como não se pode exigir do coração qualquer demonstração ou prova, não se pode confundir o "sentimento" do "coração" (seu conhecimento imediato, intuitivo) com a sensibilidade ou a imaginação, provenientes ambas de uma ação do corpo sobre a alma (cf. B. 82; L. 44). Tendo estas três ordens razões distintas, mantêm entre si uma "distância infinita": "A distância infinita dos corpos aos espíritos figura a distância infinitamente infinita dos espíritos à caridade, visto que ela é sobrenatural" (B. 793; L. 308).

Essa distância infinita entre as ordens não impede, contudo, que haja uma hierarquia entre elas. Na medida em que o homem delas participa, ele encontra-se em instâncias que, não sendo mensuráveis entre si, já que se constituem em ordens distintas, paradoxais, se relacionam com ele, porém, com valores distintos, ascendentes. De maneira simples, temos que a ordem do "coração" é superior à da razão; e esta, à do corpo. Se o corpo não pode conhecer a si mesmo, é porque só a razão o pode; contudo, se esta pode conhecer a natureza, não o pode a seus próprios princípios e ao que está acima da natureza (o "sobrenatural"), que se situa na ordem da caridade (isto é, na ordem da fé, da moral, dos costumes etc.; portanto, do "coração"). ${ }^{15}$

À luz dessa doutrina antropológica das ordens, a própria distinção pascaliana das ordens das ciências - exposta no Prefácio de Sobre o tratado do vácuo - ganha um fundamento antropológico. Se nos Pensamentos, contudo,

14 Deste modo, Pascal não rompe, mas, ao contrário, mantém - e, em certo sentido, aprofunda - o dualismo cartesiano corpo/alma, justamente na medida em que aproxima a vontade da ordem do "coração". Mais uma vez, é uma postura que difere da espinosana, que - com base na doutrina dos atributos de pensamento e extensão da substância - questiona com radicalidade a distinção substancial corpo/alma.

150 "sobrenatural" não significa aqui necessariamente o mistério divino da graça e da fé, mas também quer dizer, tão-simplesmente, o que, no âmbito dos objetos do conhecimento, está acima da natureza (a moral, os costumes, a política etc.) e o que, em correspondência, no âmbito antropológico, está acima da "luz natural". 
a ordem das ciências do raciocínio identifica-se imediatamente com a ordem da razão, a ordem das ciências da memória e da autoridade apenas aproximadamente se identifica com a ordem do "coração". Isso se deve ao caráter pouco determinado desta mesma noção. Ora, sob o nome de "coração", temos em Pascal formas ideais muito diversas: aparece ao mesmo tempo como vontade, como lugar anímico dos princípios da razão, como lugar anímico da graça da fé. Afinal, o que seria mesmo o "coração"? Nossa interpretação é que esta é uma noção que Pascal não chegou a determinar com a mesma precisão e clareza com que ele concebeu a razão e o raciocínio. No francês do século XVII, o termo cœur expressa o mais íntimo do homem, algo muito próximo do íss ánthrpos (homem interior) de Paulo; significa, pois, a vontade, a coragem, o conhecimento imediato. ${ }^{16}$ Esta é, portanto, uma noção que não separa conhecimento e ação (assim como na fé não estão separados), mas o conhecimento aqui se distingue do conhecimento demonstrativo da razão (o raciocínio), no qual, justamente, a ação lhe é exterior. Esta noção, que permanece vaga, expressa antes de tudo a busca de Pascal em ir além do raciocínio, da demonstração; enfim, em encontrar uma possibilidade de conhecimento capaz de ter como objetos o que a razão não alcança: seus próprios princípios, o estudo do homem, o problema moral, a fé. Problemas que, sabemos hoje, não têm o mesmo estatuto e que não podem, portanto, ser pensados juntos; mas que, e esta talvez seja a grande intuição de Pascal, exigem que o pensamento vá além da razão demonstrativa. Esta exigência de ultrapassar a razão geométrica é constituída justamente pela necessidade de um integral "estudo do homem", capaz de pensar suas misérias e grandezas, suas contradições e seus paradoxos, coisa que o método geométrico, fundado que é no princípio da identidade, não parece ser capaz de fazer. ${ }^{17}$

16 O uso terminológico do termo "coração" para referir-se a este âmbito mais amplo da prática (e da moral) mantém-se, ainda no século XVIII, no filósofo holandês Franz Hemsterhuis (2000), para quem o "coração" é o "órgão da moral".

17 No dizer de Silva (2001, p. x), "A compreensão do ser humano exige que se relacionem duas verdades que, no entanto, se contradizem. Como a razão tem dificuldade para aceitar que a verdadeira compreensão está em assumir a contradição, ela prefere buscar o grau de clareza relativo que pode oferecer uma explicação parcial e incompleta a enfrentar a complexidade de uma oposição irreconciliável". 
AQUINO, João Emiliano Fortaleza de. Blaise Pascal: the limits of the geometric method and the notion of "heart". Trans/Form/Ação. São Paulo, v.31(2), 2008, p. 39-59.

- ABSTRACT: This study intends to study the problem of knowledge in Blaise Pascal, according to his conception of the geometric method applied to the knowledge of nature and techniques and on his efforts for another type of knowledge that can be applied to the "supernatural" reality (faith, man, moral, customs, politics). To this intention the present study articulates an analysis of Pascal's essays: Préface. Sur le Traité du vide, De l'esprit géometrique, De l'art de persuader, and some fragments from Pensées.

- KEYWORDS: knowledge; geometric method; heart.

\section{Referências bibliográficas}

BATTISTI, César Augusto. O método de análise em Descartes: da resolução de problemas à constituição do sistema de conhecimento. Cascavel (PR): Edunioeste, 2002.

DESCARTES, René. Discurso do método; Meditações; Objeções e respostas; As paixões da alma; Cartas. Trad. br. e notas de J. Guinsburg e Bento Prado Júnior. São Paulo: Abril Cultural, 1979. (Os Pensadores).

Regras para a direção do espírito. Trad. port. de João Gama. Lisboa: EdiÇões 70, 1989.

ESPINOSA, Baruch. Correspondência. Trad. br. e notas de Marilena Chauí. In: Espinosa. São Paulo: Abril Cultural, 1983. (Os Pensadores).

FORLIN, Enéias. Entendimento, vontade e paixão em René Descartes, anotações para minicurso apresentado no I Seminário de Pesquisa do Mestrado em Filosofia da UECE, outubro de 2005, (mimeo).

HEMSTERHUIS, Franz. Sobre o homem e suas relações. Trad., apres. e notas de Pedro Paulo Pimenta. São Paulo: Iluminuras, 2000.

OLIVA, Luís César G. "O conhecimento em Pascal". In: Cadernos Espinosanos, n¹1, São Paulo, 2004.

OLIVEIRA, Manfredo Araújo. Antropologia na filosofia de Kant. A filosofia na crise da modernidade. São Paulo: Loyola, 1989.

PASCAL, Blaise. Pensées. Euvres complètes. Apres. e notas de Louis Lafuma. Paris: Seuil, 1963.

Préface. Sur le Traité du vide. Euvres complètes. Apres. e notas de Louis Lafuma. Paris: Seuil, 1963a.

De l'esprit géometrique. Euvres complètes, ed. cit., 1963b.

L'art de persuader. Euvres complètes, ed. cit., 1963c.

Pensamentos. Ed., apres. e notas de L. Lafuma; trad. br. de Mário Laranjeira. São Paulo: Martins Fontes, 2001.

Pensamentos. Trad. br. de Olívia Bauduh, de acordo com a edição de Léon Brunschwicg. São Paulo: Nova Cultural, 1999 (Os Pensadores).

SILVA, Franklin Leopoldo e. Introdução. In: PASCAL, Blaise. Pensamentos. São Paulo: Martins Fontes, 2001. 